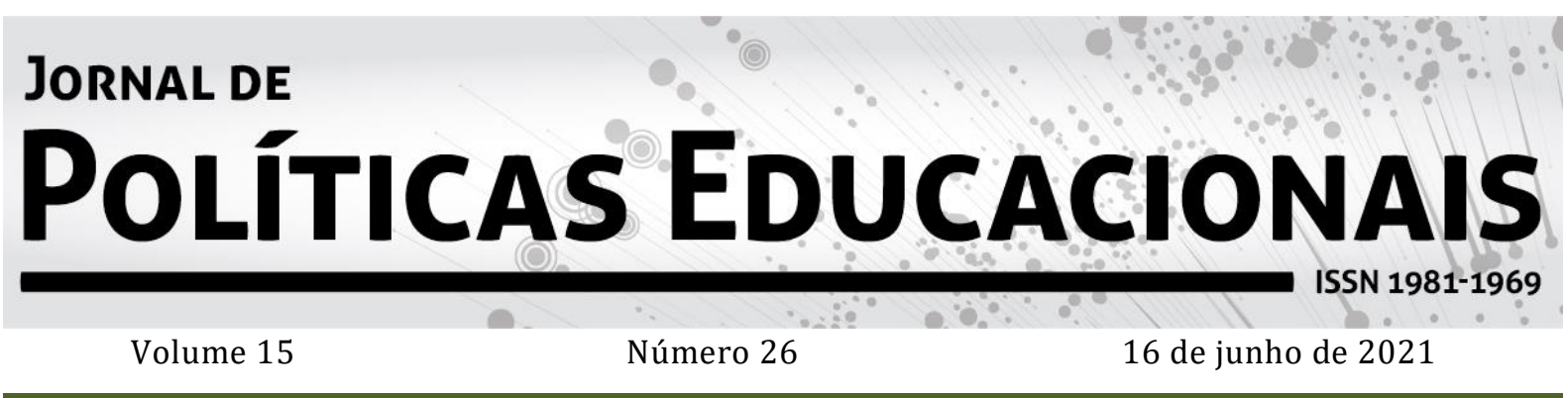

\title{
A reforma do ensino médio e a legitimação da educação a distância: o nó obsceno da mediação tecnológica
}

\section{High school reform and distance education legitimation: technologic mediation as an obscene knot}

\section{La reforma de la escuela secundaria y la legitimación de la educación a distancia: el nudo obsceno de la mediación tecnológica}

\author{
Gedeli Ferraz:o ${ }^{1}$ \\ Marco Antônio de Oliveira Gomes²
}

Citação: FERRAZZO, G.; GOMES, M. A. de O. A reforma do ensino médio e a legitimação da educação a distância: o nó obsceno da mediação tecnológica. Jornal de Políticas Educacionais. V. 15, n. 26. Junho de 2021.

\section{http://10.5380/ipe.v15i0.79897}

\section{Resumo}

0 presente trabalho tem como propósito analisar o alinhamento entre o projeto Ensino Médio com Mediação Tecnológica - EMMTec no Estado de Rondônia e a reforma do Ensino Médio. Trata-se de um assunto importante diante da urgência do enfrentamento das propostas hegemônicas que contribuem para a intensificação dos processos de precarização e mercantilização da educação pública. Desse modo,

\footnotetext{
${ }^{1}$ Mestrado em Educação pela Universidade Federal de Rondônia (2014). Atuou como professora substituta da Universidade Federal de Rondônia (UNIR) no departamento de Ciências da Educação (20112013) e na gestão de projetos de capacitação docente (RENAFOR e PACTO da Alfabetização). Coordenou o Núcleo de Desenvolvimento Territorial do Território da Cidadania Madeira Mamoré UNIR/CNPq (20152016). Atualmente é professora de Filosofia no Instituto Federal de Educação, Ciência e Tecnologia de Rondônia. Porto Velho, RO. Brasil. Orcid: https://orcid.org/0000-0002-7463-6998. E-mail: gedeli.ferrazzo@ifro.edu.br 2 Doutorado (2008) em História e Filosofia da Educação pela Universidade Estadual de Campinas (Unicamp). Atualmente é professor adjunto da Universidade Estadual de Maringá, lotado no Departamento de Fundamentos da Educação e membro do corpo docente do PPE-UEM, na linha de pesquisa: História e Historiografia da Educação. Líder do Grupo de Pesquisa "Fundamentos Históricos da Educação" - UEM/CNPq". Participa do Grupo de Pesquisas História, Sociedade e Educação no Brasil Histedbr/UNIR e do Grupo de Pesquisa sobre Política, Religião, Educação e Modernidade (Universidade Estadual de Maringá). Porto Velho, RO. Brasil. Orcid: https://orcid.org/0000-0002-2397-5615. E-mail: marcooliveiragomes@yahoo.com.br
} 
FERRAZZO, G.; GOMES, M. A. de O. A reforma do ensino médio e a legitimação da educação a distância: o nó obsceno da mediação tecnológica

organizamos o texto, inicialmente, examinando os principais documentos que orientam a atual reforma do Ensino Médio, com ênfase na regulamentação da oferta do ensino a distância ou mediado por tecnologia. Em seguida, averiguamos as formas de regulamentação e estruturação do projeto EMMTec em Rondônia. Finalizamos o texto destacando que a reforma do Ensino Médio, alicerçada na flexibilização curricular de um ensino mediado por tecnologia, representa, na prática, a homogeneização da educação a distância.

Palavras chave: Reforma do Ensino Médio. Educação a distância. Ensino Médio com Mediação Tecnológica.

\section{Abstract}

In this study, we discuss the relation between the high school with technological mediation - EMMtec in the State of Rondônia, Brazil, and the high school reform as a whole. We must face hegemonic proposals that contributes to public education's precariousness and commodification, so this discussion is important. This article is divided in two sections. In the first part, we analyze legal documents that are the base of the high school reform emphasizing high school with technological mediation, in other words, distance education. In the second part, we examine EMMtec structure and its regulation in Rondônia. In the conclusion, we argue that high school reform based on curricular flexibility in technology-mediated education presents, in fact, the homogenization of distance education.

Key words: High school reform. Distance education. High School with Technological Mediation.

\section{Resumen}

El presente trabajo tiene como objetivo analizar la alineación entre el proyecto de Bachillerato con Mediación Tecnológica - EMMTec en el Estado de Rondônia y la reforma del Bachillerato. Este es un tema importante ante la urgencia de enfrentar las propuestas hegemónicas que contribuyen a la intensificación de los procesos precarios y de comercialización de la educación pública. Así, organizamos el texto, inicialmente, examinando los principales documentos que orientan la actual reforma del Bachillerato, con énfasis en la regulación de la oferta de educación a distancia o mediada por tecnología. Luego, investigamos las formas de regulación y estructuración del proyecto EMMTec en Rondônia. Concluimos el texto señalando que la reforma de la educación secundaria, basada en la flexibilidad curricular de la enseñanza mediada por la tecnología, representa, en la práctica, la homogeneización de la educación a distancia.

Palabras Clave: Reforma de la escuela secundaria. Educación a distancia. Escuela secundaria con Mediación Tecnológica.

\section{Introdução}

A história demonstra que a relação entre capital e trabalho sofreu profundas alterações fortemente delimitadas a partir do final dos anos 1960 e início dos anos 1970, alterando de forma contundente a visão de emprego estável e permanente, materializando-se nas nações capitalistas avançadas e penetrando progressivamente nas mais diferentes regiões do planeta, configurando-se como uma nova relação entre as empresas, regulada pela desverticalização, terceirização e subcontratação da mão de obra, além da recolocação de unidades de produção para regiões que apresentassem o atrativo maior da rentabilidade do capital.

As mudanças descritas apresentaram como desdobramento a intensificação da competição, processos de fusão ou aquisição, e por fim, a aceleração da concentração econômica. A ampliação do "livre mercado" acelerou o processo de reestruturação 
FERRAZZO, G.; GOMES, M. A. de O. A reforma do ensino médio e a legitimação da educação a distância: o nó obsceno da mediação tecnológica

produtiva das empresas e contribuiu para a ampliação do desemprego e aniquilação de algumas profissões.

No âmbito da educação, o processo de reestruturação produtiva que resultou na acumulação flexível passa a exigir um projeto pedagógico alinhado com a formação de "subjetividades flexíveis", de sujeitos resignados às formas precárias e instáveis de trabalho.

São inúmeras as transformações que ocorrem no âmbito das relações de trabalho como desdobramento da reestruturação produtiva que ocorre no cenário de intensificação da mundialização econômica. No caso brasileiro, essas mudanças foram promovidas com a abertura econômica promovida pelo do governo de Fernando Collor (1990-1992), aceleradas durante a gestão de Fernando Henrique Cardoso (1995- 2002) e recentemente, solidificadas pelo governo ilegítimo de Michel Temer (2016-2018).

A partir do receituário indicado pelo capital, o governo de Michel Temer, tratou de golpear fortemente as políticas sociais, por meio da imposição de medidas austeras de desregulamentação tendo como propósito a redução do papel do Estado e dos direitos sociais em nome da lógica do mercado financeiro.

No âmbito das políticas educacionais, determinou-se um conjunto de medidas incomplacentes que culminaram nas reformas educacionais. Dentre as reformas efetivadas neste período, destaca-se a do Ensino Médio, a qual representa uma reedição perversa da reforma implementada na década de 1990. 0 primeiro ataque à educação pública, em especial ao Ensino Médio, se estabeleceu pela Medida Provisória (MP) 746, em 22/09/2016, que alterou a Lei de Diretrizes e Base da Educação Nacional (LDBEN) nº 9.394/1996, e posteriormente se transformou na Lei 13.415/2017.

Em consonância com a reforma do Ensino Médio, é expedido o decreto ${ }^{\circ}$ 9.057/2017 que estabelece o novo marco regulatório para a Educação a Distância e autoriza a oferta dessa modalidade no Ensino Médio. No mesmo ano, o governo institui, por meio do decreto n 9.204/2017, o "Programa de Inovação Educação Conectada", e regulamenta o Centro Nacional de Mídias da Educação, que promove a transmissão remota de aulas para o Ensino Médio. Tendo como corolário da reforma a aprovação do Conselho Nacional de Educação (CNE) das Diretrizes Curriculares Nacionais do Ensino Médio (DCNEM), no dia 21 de novembro de 2018.

Esse pacote de medidas que se impôs ao Ensino Médio brasileiro, ancorado no discurso ideológico do desenvolvimento produtivo do país e da autonomia de escolha dos 
jovens, reforçam as investidas do capital. Configurando-se hegemonicamente em um projeto privatista e mercadológico pautado na flexibilização curricular e na oferta do ensino a distância ou "mediado por tecnologia".

Nessa perspectiva, compreende-se que a atual reforma do Ensino Médio, pautada no princípio de flexibilização curricular e na oferta dos itinerários formativos a distância ou mediados por tecnologia, representa a legitimação do que já vem se materializando em alguns estados brasileiros sob a designação de "Ensino Médio presencial mediado/intermediado por tecnologia". Como é o caso do Amazonas, Bahia, Piauí e Rondônia, que implantaram programas de ensino mediados por tecnologia na Educação Básica.

Isto posto, o presente artigo tem como objetivo analisar o alinhamento entre $\mathrm{o}$ projeto Ensino Médio com Mediação Tecnológica - EMMTec no Estado de Rondônia e a atual reforma do Ensino Médio.

Trata-se de um assunto importante diante da urgência do enfrentamento das propostas hegemônicas que intensificam a precarização dos processos educativos e colaboram com a mercantilização da educação pública. Desse modo, organizamos o texto, inicialmente, examinando os principais documentos que orientam a atual reforma do Ensino Médio, com ênfase na regulamentação da oferta do ensino a distância ou mediado por tecnologia. Em seguida, averiguamos as formas de regulamentação e estruturação do projeto EMMTec em Rondônia. Finalizamos o texto, destacando que a reforma do Ensino Médio, alicerçada na flexibilização curricular de um ensino mediado por tecnologia, representa na prática a homogeneização da educação a distância.

\section{A reforma do Ensino Médio e a regulamentação da oferta do ensino a distância ou mediado por tecnologia}

A história da educação no Brasil e especificamente do Ensino Médio é caracterizada pela dualidade educacional, entre um modelo de ensino preparatório para os estudos superiores e a formação imediata para mercado de trabalho. Todavia, a dualidade educacional não deve ser compreendida como algo novo, pois sua gênese remonta desde a Colônia. Com efeito, verifica-se que até o início da década de 1990, o Ensino Médio de educação geral destinava-se a elite, cabendo aos jovens trabalhadores o Ensino Médio profissionalizante. 
FERRAZZO, G.; GOMES, M. A. de O. A reforma do ensino médio e a legitimação da educação a distância: o nó obsceno da mediação tecnológica

Todavia, as mudanças ocorridas no âmbito das relações de trabalho, a partir reestruturação produtiva do capital, na esteira das políticas do Banco Mundial para os países pobres, influenciaram significativamente as políticas de universalização da educação básica a partir da década de 1990.

Nesse cenário, a educação geral é referendada como estratégia para a democratização do Ensino Médio. Logo, o discurso de preparar os jovens para o mercado de trabalho, que vigorou no período da ditadura civil militar, cede lugar a tônica de prepará-los para a vida. "Sob esse ideário, preparar para a vida significaria desenvolver nas pessoas competências genéricas e flexíveis, de modo que elas pudessem se adaptar facilmente às incertezas do mundo contemporâneo" (CIAVATTA; RAMOS 2011, p. 30).

De tal modo, quando destinado aos trabalhadores, o Ensino Médio de educação geral desqualificou-se, configurando-se pela lógica da inclusão excludente, no qual se amplia o número de matrículas ao mesmo tempo em que os processos educativos são esvaziados. Kuenzer (2010) assinala esse processo pela tese da dualidade invertida, promovida a partir da acomodação do novo regime de produção flexível e regulamentada por meio do decreto $\mathrm{n}^{\circ} 2.208 / 97$, o qual desvinculou a educação profissional e tecnológica do Ensino Médio. Somente em 2004, já no governo de Luiz Inácio Lula da Silva, é sancionado o Decreto ${ }^{\circ}$ 5.154/2004 que possibilita a articulação entre educação geral e profissional mediante a modalidade "Ensino Médio integrado". No entanto, a oferta do Ensino Médio integrado é ainda limitada, embora tenha sido ampliada expressivamente com a expansão dos Institutos Federais de Educação, Ciência e Tecnologia.

Nessa direção, nos últimos anos se intensificou o debate sobre a finalidade e a concepção de Ensino Médio diante das novas possibilidades de mediação pedagógica pelas tecnologias de informação e comunicação. Na esteira desse debate, se inserem dois projetos societários de Ensino Médio. De um lado está o projeto do grupo do setor privado que defende a flexibilização do currículo em detrimento da rigidez do percurso disciplinar. De outro, está o projeto do grupo de entidades, intelectuais e educadores que historicamente sustentam a proposta de um Ensino Médio unitário que possibilite a plena formação humana.

0 debate é afastado do cenário educacional quando, de sobressalto, o governo de Michel Temer edita a medida provisória ${ }^{\circ}$ 746, de 22 de setembro de 2016, atendendo aos interesses do setor privado. Muitas críticas e questionamentos foram feitos à medida provisória, no entanto, essa culminou na promulgação da lei 13.415 de 16 de fevereiro de 
FERRAZZO, G.; GOMES, M. A. de O. A reforma do ensino médio e a legitimação da educação a distância: o nó obsceno da mediação tecnológica

2017, que instituiu a reforma do Ensino Médio, tendo como proposta principal a flexibilização curricular.

Vale registrar o fato, de que a reforma do Ensino Médio, promovida de forma apressada e autoritária pelo governo golpista de Michel Temer (2016-2018), não pode ser dissociada de outras reformas: Projeto de Lei Complementar (PLP) 257/2016, do ajuste fiscal, Proposta de Emenda Constitucional no55 e Emenda Constitucional no95, da Reforma Trabalhista e da Previdência. Trata-se de iniciativas que objetivam atender demandas do capital financeiro e reforçar a hegemonia burguesa.

A reforma do Ensino Médio foi financiada por meio de empréstimos patrocinados pelo Banco Interamericano de Desenvolvimento (BID) com apoio do Banco Internacional para Reconstrução e Desenvolvimento, uma extensão do Banco Mundial (BIRD). Na esteira do financiamento ofertado por essas instituições, se estabelecem os condicionantes à política educacional brasileira. Assim, em novembro de 2017 o Banco Mundial emite um relatório denominado "Um Ajuste Justo: Análise da eficiência e equidade do gasto público no Brasil", propondo a redução de 1,5\% do PIB em investimentos na educação básica e superior. De acordo com o relatório:

[...] As despesas públicas com ensino fundamental e médio apresentam ineficiências significativas, e o mesmo nível de serviços poderia ser prestado gastando $1 \%$ a menos do PIB em nível local. Uma análise de eficiência intermunicipal demonstra que o desempenho atual dos serviços de educação poderia ser mantido com $37 \%$ menos recursos no Ensino Fundamental e $47 \%$ menos recursos no Ensino Médio. Isso corresponde a uma economia de aproximadamente $1 \%$ do PIB. As baixas razões aluno/professor representam a principal causa de ineficiência (39\% da ineficiência total). 0 aumento do número de alunos por professor em $33 \%$ no Ensino Fundamental e 41\% no Ensino Médio economizaria R\$ 22 bilhões (0,3\% do PIB) por ano (BANCO MUNDIAL, 2017, p. 13).

Essas instituições, em decorrência do processo de intensificação da internacionalização da economia e de novos modelos de gestão e produção, buscam flexibilizar o caráter da escola por meio do enxugamento dos currículos e a desoneração do Estado no atendimento das demandas populares. A adoção de um modelo formativo pautado pelas forças do mercado, a reforma esvazia os conteúdos e promove o reforço de uma formação aligeirada.

Para tanto, a reforma do Ensino Médio forjada sob o discurso midiático de liberdade de escolhas aos jovens e de um Ensino Médio atrativo pela oferta de diferentes itinerários formativos, configura-se em um projeto privatista e mercadológico, que por 
meio da flexibilização curricular, não apenas reduzirá os conteúdos historicamente sistematizados, mas impedirá o acesso a esses.

0 princípio da flexibilização curricular, que organiza a reforma do Ensino Médio levada a efeito pela Lei no $13.415 / 2017$, insere-se em um quadro conceitual mais amplo: o da aprendizagem flexível, concebida como resultado de uma metodologia inovadora, que articula o desenvolvimento tecnológico, a diversidade de modelos dinamizadores da aprendizagem e as mídias interativas; neste caso, ela se justifica pela necessidade de expandir o ensino para atender às demandas de uma sociedade cada vez mais exigente e competitiva (KUENZER, 2017, p. 337).

Se para muitos educadores a reforma do Ensino Médio é inviável de ser implementada devido a falta de infraestrutura e de recursos humanos na oferta dos distintos itinerários formativos e no fomento as escolas de Ensino Médio em tempo integral. Partimos da proposição de que a reforma será viabilizada por meio da educação a distância ou mediada por tecnologia, uma realidade em diversos Estados brasileiros que ofertam o Ensino Médio por meio de programas no formato EaD.

Não por acaso, a reforma prevê a oferta de cursos por meio de educação a distância ou educação presencial mediada por tecnologias, no cumprimento às exigências curriculares.

Art. 36. § 11. Para efeito de cumprimento das exigências curriculares do Ensino Médio, os sistemas de ensino poderão reconhecer competências e firmar convênios com instituições de educação a distância com notório reconhecimento, mediante as seguintes formas de comprovação: VI cursos realizados por meio de educação a distância ou educação presencial mediada por tecnologias (BRASIL, 2017, grifos dos autores).

Nesses termos, para assegurar a objetivação da EaD no Ensino Médio, é sancionado o decreto $n^{\circ} 9.057$ de 26 de maio de 2017, o qual regulariza a oferta da educação básica na modalidade a distância, cabendo aos sistemas de ensino estaduais e municipais autorizar cursos e o funcionamento das instituições de educação a distância, observando os termos contidos no $§ 11$ do art. 36 da LDBEN n 9.394/1996, conforme citado anteriormente.

Nessa mesma direção, as diretrizes curriculares nacionais do Ensino Médio (DCNEM), estabelecidas pelo Conselho Nacional de Educação por meio da resolução nํㅜ 3, de 21 de novembro de 2018, também legitimam a oferta da educação a distância:

Art. 17. § 15. As atividades realizadas a distância podem contemplar até $20 \%$ (vinte por cento) da carga horária total, podendo incidir tanto na 
FERRAZZO, G.; GOMES, M. A. de O. A reforma do ensino médio e a legitimação da educação a distância: o nó obsceno da mediação tecnológica

formação geral básica quanto, preferencialmente, nos itinerários formativos do currículo, desde que haja suporte tecnológico - digital ou não - e pedagógico apropriado, necessariamente com acompanhamento/coordenação de docente da unidade escolar onde o estudante está matriculado, podendo a critério dos sistemas de ensino expandir para até 30\% (trinta por cento) no Ensino Médio noturno. [...] Na modalidade de educação de jovens e adultos é possível oferecer até 80\% (oitenta por cento) de sua carga horária a distância (BRASIL, 2018, p. 10-11).

De acordo com Cesar Callegari, ex-membro do CNE, em entrevista à Folha de São Paulo, o texto aprovado fomenta a privatização da educação por meio da atuação de grupos privados nas atividades a distância: "Os acionistas de empresas educacionais devem estar em festa, porque abre um caminho enorme da educação a distância dentro da educação básica” (FOLHA DE SÃO PAULO, 08/11/2018).

Mais uma vez, as promessas de liberdade e qualidade enfatizadas pela propaganda e em diferentes veículos de comunicação não passam de palavras vazias que enxergam na educação mais um segmento do mercado que pode ser amplamente explorado.

Em consonância aos pressupostos da reforma do Ensino Médio e a legitimação da EaD, no dia 23 de dezembro de 2017 é instituído, por meio do decreto ${ }^{\circ}$ 9.204/2017, o "Programa de Inovação Educação Conectada", tendo como um dos seus objetivos fomentar o uso de tecnologia digital na Educação Básica. Por meio do programa, o Ministério da Educação (MEC), em conjunto com o Conselho Nacional de Secretários de Educação (Consed) e com o apoio da TV Escola e da Fundação Roberto Marinho, criou o Centro Nacional de Mídias da Educação (CNME), fomentando a oferta do Ensino Médio presencial mediado por tecnologia.

A análise desenvolvida até aqui já delineia alguns pontos importantes no que se refere à implementação da reforma do Ensino Médio por meio da EaD ou mediada por tecnologia. Todavia, parte-se da hipótese de que a regulamentação da oferta do Ensino Médio a distância, promovida pelas reformas educacionais supracitadas, representam a legitimação do que já vem se materializando em alguns estados brasileiros sob a designação de "Ensino Médio presencial mediado/intermediado por tecnologia". Como é o caso do Estado de Rondônia, que em 2016, implantou o Ensino Médio com mediação tecnológica, enquanto proposta de universalização da educação básica, questão sobre a qual nos deteremos a seguir. 
FERRAZZO, G.; GOMES, M. A. de O. A reforma do ensino médio e a legitimação da educação a distância: o nó obsceno da mediação tecnológica

\section{Ensino Médio com mediação tecnológica em Rondônia}

O Brasil, segundo os resultados do Censo 2010, possui cerca de 9\% da população com dez anos ou mais na condição de analfabeto, o que equivale dizer que aproximadamente 18 milhões de brasileiros não sabem ler e escrever. Segundo Hentges (2011), seriam 16 milhões de analfabetos com 15 anos ou mais e 30 milhões de analfabetos funcionais. Os dados acima expressam a desigualdade brutal materializada no âmbito da educação escolar, o que impulsiona o Estado a propor alternativas paliativas para solução do problema.

Nesse contexto, o Estado de Rondônia por meio da Secretaria Estadual de Educação (SEDUC-RO), no ano de 2016, implantou o projeto Ensino Médio com Mediação Tecnológica, tendo como objetivo "Implantar o Ensino Médio com Mediação Tecnológica” nos municípios e respectivas zonas rurais, conforme orienta o princípio constitucional quanto à obrigatoriedade gradativa da universalização do Ensino Médio até 2016". Para tanto, o projeto se:

[...] constitui enquanto uma alternativa administrativo-pedagógica para garantir o acesso e assegurar a qualidade no atendimento dos alunos concluintes do Ensino Fundamental, das comunidades rurais, cuja oferta atual enfrenta além dos problemas qualitativos, a falta de vagas para atender a demanda e também para atender excepcionalmente a área urbana, nos municípios interioranos, haja vista que o déficit de professores habilitados atinge vários componentes curriculares do Ensino Médio (RONDÔNIA, 2016a, grifos dos autores).

Diante do anunciado déficit de professores na rede pública e da proclamada dificuldade de acesso a determinadas áreas do Estado de Rondônia, a Secretaria da Educação do Estado de Rondônia lançou o projeto Ensino Médio com Mediação Tecnológica. No entanto, o projeto original surgiu em 2013, sendo submetido para apreciação e aprovação do Conselho Estadual de Educação (CEE/RO) sob o título "Projeto de Implantação do Curso Ensino Médio presencial com Mediação Tecnológica”, tendo como objetivo "Implantar o Ensino Médio Presencial com Mediação Tecnológica nos municípios e respectivas zonas rurais, conforme orienta o princípio constitucional quanto à obrigatoriedade gradativa da universalização do Ensino Médio até 2016

Após análise e parecer 032/2013 CEE/RO do conselheiro João Romão, representante do Sindicato Estadual dos Professores (SINTERO), o projeto foi aprovado com a ressalva de que se suprimisse do título a palavra "Presencial", mantendo-se apenas 
FERRAZZO, G.; GOMES, M. A. de O. A reforma do ensino médio e a legitimação da educação a distância: o nó obsceno da mediação tecnológica

“Projeto de Implantação do Curso Ensino Médio com Mediação Tecnológica”. No entanto, a Secretaria do Estado não conseguiu viabilizar a implantação do projeto por falta de recursos na infraestrutura para acomodação de um estúdio. Apenas em 2015, após a assinatura do termo de cooperação com o Instituto Federal de Ciência e Tecnologia de Rondônia (IFRO), o qual teve como objeto o pagamento para utilização do estúdio do IFRO, é que o projeto caminhou para implantação.

Vale destacar que nesse percurso de aprovação do projeto e implantação, diversos movimentos sociais, principalmente do campo, se manifestaram contra o projeto buscando formas legais de garantir a participação na proposição de outras medidas para a universalização da educação básica.

Contudo, todas as tentativas foram frustradas já que, em Rondônia, a instância participativa para deliberação e normatização da educação - o Conselho Estadual de Educação - se materializou em uma instância sem representação da sociedade civil, sendo um colegiado com grande porcentagem de conselheiros indicados pelo governo do Estado, o que reitera a premissa de um órgão que existe apenas para referendar as necessidades do poder estatal.

Isto posto, em março de 2016, o projeto foi implantado em 85 (oitenta e cinco) escolas estaduais de Rondônia por meio da portaria no 680/2016-GAB/SEDUC de 08 de março de 2016, que "Implanta o Ensino Médio com Mediação Tecnológica nas escolas da rede pública estadual de ensino". Todavia, o projeto implantando não correspondia ao projeto aprovado no CEE/RO, o que levou a SEDUC a submeter um novo projeto, agora sob o nome "Projeto de Ensino Médio com Mediação Tecnológica" ao CEE/RO para regulamentar as alterações do projeto em curso.

Em vista disso, no dia 23 de maio de 2016, o projeto alterado foi submetido para a aprovação do CEE/RO, momento este em que diversos movimentos sociais se reuniram solicitando a suspensão imediata do projeto em curso. 0 resultado das manifestações culminou na prorrogação da votação do projeto pelo CEE/RO por 45 dias, prazo estabelecido para se discutir com a sociedade o projeto.

Diversas ações de mobilização para discussão do projeto foram promovidas no Estado, principalmente com as comunidades do campo, o público-alvo. Tais ações culminaram na proposição de uma audiência pública na Assembleia Legislativa do Estado de Rondônia, realizada no dia 23 de junho de 2016, a qual reuniu diversos movimentos sociais, os grupos de pesquisas da Universidade Federal de Rondônia, alunos e 
professores, Ministério Público Estadual de Rondônia e a parte interessada, a SEDUC. Após quatro horas interruptas de debate e considerações ao projeto, com a participação de apenas três deputados estaduais, a audiência foi encerrada com a proposição de construção de um novo projeto com a participação dos movimentos sociais.

No entanto, no dia 06 de junho de 2016, data anterior à audiência pública, o CEE/RO encaminhou à SEDUC o projeto em diligência, por meio do Ofício 315/16 CEE/RO, a fim de que a SEDUC promovesse ajustes no projeto e providências indicadas no ofício. Dentre as principais indicações feitas pelo CEE, constava a publicação legal da criação do EMMTec, com retroatividade a o início de sua implantação. Diante das providências indicadas pelo CEE/RO, a primeira medida tomada pela SEDUC foi publicar o ato legal de criação do projeto. Para tanto, foi encaminhado à Assembleia Legislativa de Rondônia, no dia 14 de junho de 2016, o Projeto de Lei (PL) 424/2016.

A tramitação do projeto na Assembleia Legislativa do Estado de Rondônia ocorreu com grande celeridade. Em 21 de junho de 2016, data que precedia a audiência pública agendada para discutir o projeto, o PL 424/2016 foi encaminhado para parecer da Comissão de Constituição e Justiça e de Redação, sendo inserida no mesmo dia para aprovação da Plenária. No entanto, ocorreu o pedido de vistas do deputado Jesuíno Boabaid (PT do B) sobre a justificativa de que a casa iria discutir o projeto em pauta no dia 23 de junho de 2016 em audiência pública.

Conforme previsto, a audiência pública ocorreu no dia 23 de junho de 2016, contando com a presença maciça dos movimentos sociais, da universidade, Ministério Público Estadual, professores e alunos. Sobre gritos de protestos, a Secretaria de Educação de Rondônia apresentou o projeto. Em sua apresentação foi possível constatar que a finalidade real do projeto se resume em enxugar recursos para a educação do Estado.

A audiência pública teve como resultado a elaboração de um documento com as proposições apresentadas, a saber: criação de um projeto para a formação de professores para a Educação do Campo; a implantação de uma coordenadoria de educação voltada para o campo; a valorização dos educandos do curso de licenciamento em Educação do Campo-UNIR; o cumprimento da Lei de Diretrizes de Base que trata a Educação do Campo; a elaboração de um Termo de Ajuste de Conduta (TAC) entre os envolvidos na educação para estabelecer critérios no projeto de Mediação Tecnológica (RONDÔNIA, 2016c). 
FERRAZZO, G.; GOMES, M. A. de O. A reforma do ensino médio e a legitimação da educação a distância: o nó obsceno da mediação tecnológica

Adverso às proposições supracitadas, no dia 28 de junho de 2016 o PL 424/2016 seguiu para a deliberação da Assembleia Legislativa do Estado. Na tentativa de impedir a mobilização dos segmentos organizados contrários, o PL não constou na pauta da $35^{\circ}$ sessão, o que de fato, inviabilizou a participação de grande parte dos movimentos sociais. No entanto, um grupo pequeno dos movimentos sociais presentes protestou pela necessidade de os deputados estudarem a fundo o projeto, já que na audiência pública apenas três deputados compareceram. As atrativas evidenciaram a verdadeira faceta do poder legislativo no estado de Rondônia. Desconhecendo o projeto e sua implantação irregular, os deputados referendaram a solicitação do Governo do Estado com a aprovação do projeto por 20 votos favoráveis e quatro contrários.

É passível de constatação que em Rondônia, assim como em qualquer estado burguês, o Legislativo se organiza de forma a defender os interesses econômicos da classe que representa. A igualdade política meramente formal é incapaz de impedir o domínio de classe que também se expressa na esfera legislativa. Não por acaso, sob o manto da democracia, referenda-se a ausência de uma escolha real, de modo que a democracia posta apenas contribui eficientemente para a legitimação da ordem burguesa. Com efeito, a Lei no 3.846, de 4 de julho de 2016, instituiu:

Projeto Ensino Médio com Mediação Tecnológica no âmbito da Secretaria de Estado da Educação - SEDUC, com o objetivo de implantar o Ensino Médio com Mediação Tecnológica aos estudantes que residem na zona rural, cujas localidades são de difícil acesso, com demanda reprimida ou em localidades onde houver carência de profissionais habilitados (RONDÔNIA, 2016d, p.1)

Da mesma forma, a ênfase anunciada para implantação do projeto recai na ampliação do atendimento educacional nas comunidades rurais:

[...] Objetivando solucionar essa problemática educacional e estabelecer avanços substanciais na ampliação do atendimento nas comunidades rurais, o Governo do Estado, por meio da SEDUC/RO, em parceria com o IFRO, com o fulcro na resolução ${ }^{\circ} 1$ de 02 de fevereiro de 2016, propõe a implantação do Ensino Médio regular concomitante ao ensino profissional com Mediação Tecnológica, tendo como firme propósito garantir condições sociais dignas para os jovens das populações rurais, oferecendo-lhes uma educação com padrão de qualidade que possibilite a continuidade dos estudos, a construção e reconstrução de conhecimentos para o exercício da cidadania, oportunizando a inserção no mercado de trabalho e desenvolvimento econômico do Estado (RONDÔNIA, 2016a). 
FERRAZZO, G.; GOMES, M. A. de O. A reforma do ensino médio e a legitimação da educação a distância: o nó obsceno da mediação tecnológica

Podemos inferir que, divergente do disposto tanto na lei $\mathrm{n}^{\mathrm{o}} 3.846 / 2016$ como na proposta da SEDUC/RO, que visa disponibilizar "o Ensino Médio com Mediação Tecnológica aos estudantes que residem na zona rural, em regiões de difícil acesso", o EMMTec está sendo operacionalizado tanto em escolas urbanas como em escolas rurais de fácil acesso.

No que tange ao atendimento às comunidades rurais de "difícil acesso", é imperativo destacar que Rondônia lidera o ranking nacional com 49\% de escolas do campo inativas no ano de 2013. Tal dado reitera os resultados do Panorama da Educação do Campo referente às condições precárias das escolas do campo, a dificuldade do acesso dos professores e alunos às escolas em razão da falta de um sistema adequado de transporte escolar, salários baixos dos professores com elevada carga de trabalho, quando comparada com a dos professores que atuam na zona urbana (INEP, 2007).

Todavia, esses dados são omitidos pela SEDUC/RO, não tomando como base a realidade efetiva da educação do campo no estado. 0 que reitera a premissa de um projeto de "gabinete" que não conversa com a realidade das escolas de Rondônia, principalmente com as escolas do campo, as quais não dispõem de infraestrutura adequada para a introdução de um projeto sustentado na premissa da educação a distância.

Isto posto, reitera-se que se trata de mais um projeto concebido no plano ideal que não traduz a realidade material da educação pública, consagrando o caráter obsceno abalizado pelo discurso da "igualdade de oportunidades", o qual não garante nem permanência muito menos sucesso. Contrário ao que é anunciado no projeto, trata-se de mais um projeto que visa ampliar a dualidade educacional no Estado.

Logo, a exceção se tornou regra, de modo que o projeto se pauta em um plano estratégico de cunho administrativo que nem de longe expressa uma proposta pedagógica. Isso é evidenciado na fala da secretária de Educação do Estado, Aparecida de Fátima Gavioli Soares Pereira:

[...] um comparativo econômico: são 80 escolas que são assistidas pelo projeto. Nós temos oito professores habilitados para atender toda a nossa grade curricular; seria necessário, hoje, contratar 712 professores. Se nós tivéssemos que suspender a Mediação hoje, eu teria que colocar para dentro 712 professores. Supondo que precisássemos contratar quatro profissionais para cada unidade, com uma média de salário que nós temos hoje na Folha, nós teríamos ali $\mathrm{R} \$ 1.068 .000,00$ por mês; o que vale a $\mathrm{R} \$ 13.884 .000,00$ por ano, e o que vale o período do contrato com o Instituto Federal a R\$41.652.000,00. Então vejam os senhores, com a 
FERRAZZO, G.; GOMES, M. A. de O. A reforma do ensino médio e a legitimação da educação a distância: o nó obsceno da mediação tecnológica

Mediação eu vou gastar vinte e com a não Mediação, correndo o risco de fazer concurso e o cara nem estar lá para dar aula $\mathrm{R} \$ 41.752 .000,00$ (RONDÔNIA, 2016c, p. 2720).

O discurso oficial do Estado traduz a matriz neoliberal que se estabeleceu historicamente, condicionada às demandas do mercado, com vistas ao enxugamento dos gastos públicos e pautada em uma educação "flexível". A proclamada qualidade do ensino é deduzida a partir de indicadores quantitativos, de modo que o aviltamento dos conteúdos não é colocado em discussão pelo Estado, bem como as condições físicas dos prédios escolares e os salários dos professores aviltados. Note-se, portanto, que a expansão escolar, por meio do EMMTec, pautada pela racionalização administrativa, financeira e pedagógica, reitera a premissa de uma "ampliação para menos", de modo a "torná-la permeável a novas e reiteradas utilizações privadas e instrumentais, empobrecedoras" (ALGEBAILE, 2004, p. 327).

Essa ampliação para menos se configura no Ensino Médio em Rondônia onde a universalização dessa etapa da educação básica se concentra na viabilidade econômica em detrimento as demandas pedagógicas de desenvolvimento social. A tabela 1 representa a evolução no número de matrículas no EMMTec, o que reitera a tese da substituição da oferta do Ensino Médio regular pelo Ensino Médio por mediação tecnológica.

Tabela 1 - Evolução das matrículas no EMMTec no Estado de Rondônia

\begin{tabular}{cccc}
\hline ANO & $\begin{array}{c}\text { Matrículas no Ensino } \\
\text { Médio regular rede } \\
\text { estadual-RO }\end{array}$ & $\begin{array}{c}\text { Matrículas no } \\
\text { EMMTec }\end{array}$ & $\begin{array}{c}\text { Número de escolas } \\
\text { com EMMTec }\end{array}$ \\
\hline 2016 & 52.988 & 2.002 & 85 \\
\hline 2017 & 52.797 & 4.366 & 122 \\
\hline 2018 & 51.468 & 5.134 & 114 \\
\hline 2019 & 53.278 & 5.581 & 140 \\
\hline
\end{tabular}

Fonte: SEDUC/RO

Diante do exposto, se reforça a ênfase sobre a expansão precária do Ensino Médio alicerçada na "mediação tecnológica", o que na prática corresponde a massificação do ensino a distância para a elevação dos índices de desenvolvimento escolar.

[...] assim como o capital, no seu processo de acumulação, concentração e centralização pelo trabalho produtivo vai exigindo cada vez mais, contraditoriamente, trabalho improdutivo, como se fossem verso e anverso de uma mesma medalha, a "improdutividade da escola" parece constituir, dentro desse processo, uma mediação necessária e produtiva 
FERRAZZO, G.; GOMES, M. A. de O. A reforma do ensino médio e a legitimação da educação a distância: o nó obsceno da mediação tecnológica

para a manutenção das relações capitalistas de produção (FRIGOTTO, 2010, p. 152).

Desse modo, a argumentação paira na superfície mesmo quando questões importantes são levantadas tais como as condições das escolas, os problemas de transporte escolar e o déficit de professores.

Quanto ao "déficit de professores habilitados", anunciado no projeto enquanto justificativa para sua implantação, o documento omite, por exemplo, a ausência de concursos públicos para provimento de vagas, a demissão em massa de professores temporários no ano de 2016, assim como a questão salarial, plano de carreira e condições de trabalho.

Outra questão sobre a qual refletir é sobre a organização metodológica do projeto. As disciplinas são ofertadas de forma modular, o processo de ensinoaprendizagem se estabelece por meio de televisão via satélite, entre o professor ministrante e o aluno, sendo as aulas ministradas por um professor no estúdio em Porto Velho-RO, as quais o aluno assiste na sala da escola de sua comunidade, sob orientação de um professor que estará presente em sala, chamado de professor presencial. Para tanto, o projeto se ampara no ensino por meio de:

[...] telecomunicação, para oferecer a veiculação de conteúdo programático modular/ano, por meio de Solução de Videoconferência, incluindo acesso simultâneo à Internet em Banda Larga \& Alocação de equipe multidisciplinar para apoiar a coordenação pedagógica da SEDUC/RO na implantação e operacionalização do projeto (RONDÔNIA, 2016a).

De acordo com o referido projeto, sua oferta não pretende seguir os moldes convencionais da $\mathrm{EaD}$, em que não há interatividade entre os envolvidos em sala de aula, nem mesmo a obrigatoriedade de frequência. Contudo, cabe destacar o eufemismo contido no termo "mediação tecnológica", já que tal modalidade de ensino não está prevista na LDB 9.394/1996. A legislação brasileira prevê, apenas, dois tipos de modalidades de ensino: presencial e a distância. Em nenhum momento estabelece a "mediação tecnológica" enquanto uma modalidade de oferta do ensino, haja vista que a mediação se insere enquanto uma ferramenta didática.

É consenso afirmar que as ferramentas didático-tecnológicas se estabelecem enquanto um meio para potencializar o processo de ensino-aprendizagem. No entanto as mesmas não podem ser tratadas como modalidades de ensino. 
FERRAZZO, G.; GOMES, M. A. de O. A reforma do ensino médio e a legitimação da educação a distância: o nó obsceno da mediação tecnológica

No que se refere ao material didático, anunciado no projeto (a saber: livros fornecidos pela SEDUC, materiais de apoio produzidos pelos professores ministrantes e notebooks para os alunos), constatou-se que o material didático disponível aos estudantes são reproduções dos slides utilizados pelos professores ministrantes. Tal dado evidencia o caráter fragmentado e simplista dessa proposta. Se considerarmos que:

O manual didático surgiu com a pretensão de consubstanciar uma síntese dos conhecimentos humanos de uma forma mais adequada ao desenvolvimento e à assimilação da criança e do jovem [...] Ao realizar um certo grau de simplificação e de objetivação do trabalho didático, o manual possibilitou a queda dos custos da instrução pública (ALVES, 2006, p.76-77).

É passível de constatação que a escola ignorou e deixou de incorporar ao processo de ensino-aprendizagem os avanços tecnológicos produzidos pela humanidade. No entanto, no que se refere ao EMMTec, este não se estabelece com o intuito de romper com a lógica da simplificação e da objetificação do trabalho didático, mas, ao contrário, continua a reproduzir um processo conservador no qual compreende os alunos apenas como meros receptores de informação. Com efeito, se dogmatiza o processo de ensinoaprendizagem pela padronização, o que impossibilita a compreensão que as situações que se apresentam em cada região, em cada escola, são únicas e exigem respostas únicas e não padronizadas.

É consenso afirmar que as ferramentas didáticas tecnológicas, se estabelecem enquanto um meio para potencializar o processo de ensino-aprendizagem. No entanto, no caso do EMMTec, o que se verificou é que esse projeto se converte em um fim em si mesmo, descaracterizando o papel da escola no processo de produção conhecimento e anulando os sujeitos desse processo.

Fica claro, em nossa análise, a existência de uma escola de classe. Trata-se de um fenômeno que traduz uma manifestação singular de uma situação universal. No cenário brasileiro, e mais especificamente em Rondônia, há uma escola que atende aos interesses dos filhos da burguesia, que é a escola com o perfil de continuidade, ou seja, que possibilita o acesso aos cursos mais concorridos das universidades públicas. E, no sentido oposto, uma escola que atende precariamente aos filhos da classe trabalhadora, que objetiva formá-los para o mercado flexibilizado. Saliente-se, que não há impedimento legal para os filhos de trabalhadores frequentarem e concluírem qualquer curso nas universidades 
FERRAZZO, G.; GOMES, M. A. de O. A reforma do ensino médio e a legitimação da educação a distância: o nó obsceno da mediação tecnológica

brasileiras, mas certamente as condições materiais de existência e formação escolar constituem-se em grande obstáculo.

\section{Considerações Finais}

Como síntese provisória deste artigo, é possível afirmar que, na conjuntura contemporânea, as políticas destinadas à educação do trabalhador apontam para a desresponsabilização do Estado na questão do fomento de uma educação pública, ao mesmo tempo em que verifica a responsabilização do indivíduo pelo êxito ou fracasso de sua formação. Dessa forma, a reforma do Ensino Médio como o EMMTec, não podem serem compreendidos isoladamente nem desvinculados da crise estrutural do capitalismo e do avanço conservador que observamos no embate das lutas de classe atualmente. No campo educacional, verifica-se a hegemonia das proposições liberais que fazem da escola pública brasileira um laboratório de experiências que contribuem para a desqualificação da educação pública, gratuita, universal e democrática.

A análise levada a efeito nos itens anteriores, evidencia o alinhamento da reforma do Ensino Médio às proposições de programas como o EMMTec no Estado de Rondônia. 0 primeiro elemento que aproxima a reforma do Ensino Médio às proposições do EMMTec é o discurso do ensino mediado por tecnologia, que na prática corresponde a homogeneização da $\mathrm{EaD}$ e na padronização do currículo. 0 segundo se ancora no fetichismo da tecnologia educacional, o qual apregoa às tecnologias da informação e comunicação o poder redentor de democratização do ensino. 0 terceiro se estabelece na estruturação do currículo de forma modular, onde as disciplinas são ofertadas de forma condensada. Por fim, destacamos o elemento da desqualificação da formação e do trabalho docente, alicerçada na contratação de docentes com "notório saber" por meio do trabalho temporário, casual, terceirizado ou subcontratado. Essa interface, apresenta-se, também, no EMMTec, com a redução do quadro docente e a substituição de professores habilitados em sala de aula por televisores.

Logo, a reforma do Ensino Médio e a regulamentação da oferta do ensino a distância ou mediado por tecnologia expressam a continuidade de um projeto educacional que reforça as diferenças de classes e agrava a dualidade educacional.

Diante da análise que realizamos e reforçando a importância da resistência frente ao momento atual, é necessário lembrarmos as lutas travadas pela efetivação da educação 
FERRAZZO, G.; GOMES, M. A. de O. A reforma do ensino médio e a legitimação da educação a distância: o nó obsceno da mediação tecnológica

pública, que ainda falta muito por se materializar. 0 discurso da "falta de dinheiro" escamoteia os interesses de abertura do mercado para os interesses privados. Por isso, o acesso ao conhecimento socialmente produzido pela humanidade é uma necessidade. No entanto, tal proposição não implica em uma adesão aos pressupostos da "escola redentora", que enxergam um poder redentor ou quase mítico da escola. É importante ressaltar que, se a educação não possui o caráter milagroso a ela atribuído, tampouco será possível a elevação cultural do trabalhador sem conquistarmos o espaço escolar. Se por um lado, o Estado burguês não possui condições de suprimir as profundas desigualdades econômicas pela educação, por outro lado, a escola não pode ser encarada como uma simples reprodutora das concepções de mundo das classes dominantes. Se essa assertiva fosse verdadeira, estaria negado aqui o próprio materialismo histórico e dialético.

Nessa perspectiva, a análise empreendida se constitui como parte da luta de resistência à contrarreforma do ensino médio e ao desmonte da educação pública, visando fomentar a possibilidade concreta de outro modelo de formação comprometido com o desenbolvimento omnilateral do homem.

\section{Referências}

ALGEBAILE, E. B. Escola pública e pobreza no Brasil: expansão escolar e formação da escola dos pobres no Brasil. Tese (Doutorado em Educação) - UFF, Rio de Janeiro, 2004.

ALVES, G. L. A produção da escola pública contemporânea. 3.ed. Campinas: Autores Associados, 2006.

BANCO MUNDIAL. Um ajuste justo: análise da eficiência e equidade do gasto público no Brasi.: v. 1. [S. l.]: Banco Mundial, 2017.

BRASIL. Lei $\mathbf{N}^{\circ}$ 9.394, de 20 de dezembro de 1996. Estabelece as diretrizes e bases da educação nacional. Brasília: Ministério da Educação e Cultura, 1996. Disponível em: http://www.planalto.gov.br/ccivil 03/Leis/L9394.htm>. Acesso em 18/12/2020.

BRASIL. Decreto n.o 2.208, de 17 de abril de 1997. Brasília, 1997. Disponível em: https://www.planalto.gov.br/ccivil 03/decreto/d2208.htm. Acesso em: 28/01/2021.

BRASIL. Decreto no 5.154 de 23 de julho de 2004. Brasília, 2004. Disponível em: http://www.planalto.gov.br/ccivil 03/ ato2004-2006/2004/decreto/d5154.htm. Acesso em: 28/01/2021. 
FERRAZZO, G.; GOMES, M. A. de O. A reforma do ensino médio e a legitimação da educação a distância: o nó obsceno da mediação tecnológica

BRASIL. Medida Provisória no 746, de 22 de setembro de 2016. Brasília, 2016. Disponível em: https://www25.senado.leg.br/web/atividade/materias//materia/126992. Acesso em: 14 mar 2017.

BRASIL. Lei no 13.415, de 16 de fevereiro de 2017. Brasília, 2017. Disponível em: http://www.planalto.gov.br/ccivil 03/ ato2015-2018/2017/lei/L13415.htm. Acesso em: 14/04/2017.

BRASIL. Decreto n. 9.057, de 25 de maio de 2017. Regulamenta o art. 80 da Lei no 9.394, de 20 de dezembro de 1996, que estabelece as diretrizes e bases da educação nacional. Disponível em: http://www.planalto.gov.br/ccivil 03/Ato20152018/2017/Decreto/D9057.htm. Acesso em: 29/12/2020.

BRASIL. Decreto no 9.204, de 23 de novembro de 2017. Inovação Educação Conectada e dá outras providências. Disponível em: http://www.planalto.gov.br/ccivil 03/ ato2015-2018/2017/decreto/D9204.htm. Acesso em: 03/01/2021.

BRASIL. Ministério da Educação e Conselho Nacional de Educação Câmara de Educação Básica. RESOLUÇÃO № 03/2018. Atualiza as Diretrizes Curriculares Nacionais para o Ensino Médio. Brasília, 2018. Disponível em: http://portal.mec.gov.br/conaes-comissaonacional-de-avaliacao-da-educacao-superior/323-secretarias-112877938/orgaosvinculados-82187207/59321-resolucoes-ceb-2018. Acesso em: 15/04/2019.

BRASIL. Instituto Nacional de Estudos e Pesquisa Educacional Anísio Teixeira (Inep). Censo Escolar da Educação Básica/Notas Estatísticas. Brasília, DF: Inep, 2019. Disponível em: http://portal.inep.gov.br/informacao-da-publicacao/Lasset publisher/6JYIsGMAMkW1/document/id/6798882. Acesso em: 28/12/2020.

CIAVATTA, M; RAMOS, M. Ensino Médio e Educação Profissional no Brasil: Dualidade e fragmentação. Revista Retratos da Escola, Brasília, v. 5, n. 8, p. 27-41, jan./jun. 2011. Disponível em: <www.esforce.org.br/index.php/semestral/article/download/45/42>. Acesso em: 26/01/2021.

FOLHA DE SÃO PAULO. Conselho de educação libera até $\mathbf{3 0 \%}$ de cursos a distância no Ensino Médio. São Paulo: Grupo Folha, 08/11/2018. Disponível em: https://www1.folha.uol.com.br/educacao/2018/11/conselho-de-educacao-libera-ate30-de-curso-a-distancia-no-ensino-medio.shtml. Acesso em: 12/01/2021.

FRIGOTTO, G. A produtividade da escola improdutiva. 9a Ed. São Paulo: Cortez, 2010. HENTGES, G. L. Educação no Brasil hoje: a possibilidade de uma formação de qualidade. Disponível em:http://www.webartigos.com/artigos/educacao-no-brasilhoje-a-possibilidade-de-uma-formacao-de-qualidade/65422/.Acesso em: 15 mai. 2017.

INEP. Instituto Nacional de Estudos e Pesquisas Educacionais Anísio Teixeira.

Panorama da Educação do Campo. INEP. Brasília: 2007.

KUENZER, A. Z. O Ensino Médio no Plano Nacional de Educação 2011-2020: superando a década perdida? Educação \& Sociedade, 2010, vol.31, n.112, pp.851-873. Disponível 
em: https://www.scielo.br/scielo.php?pid=S0101-

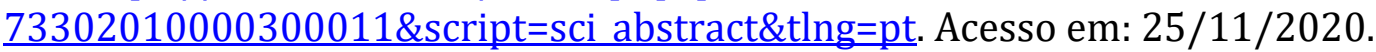

\section{KUENZER, A. Z. TRABALHO E ESCOLA: A FLEXIBILIZAÇÃO DO ENSINO MÉDIO NO} CONTEXTO DO REGIME DE ACUMULAÇÃo FLEXÍVEL. Educação \& Sociedade. 2017, vol.38, n.139, pp.331-354. Disponível em: https://www.scielo.br/scielo.php?pid=S010173302017000200331\&script=sci abstract\&tlng=pt. Acesso em 02/01/2021.

MARX, K.; ENGELS, F. A ideologia alemã. São Paulo: Boitempo, 2007. RONDÔNIA. Secretaria de Estado da Educação. Projeto de implantação do curso Ensino Médio presencial com mediação tecnológica. 2013.

RONDÔNIA. Secretaria de Estado da Educação. Projeto de Ensino Médio com mediação Tecnológica. 2016a.

RONDÔNIA. Secretaria de Estado da Educação. Portaria no 680/2016-GAB/SEDUC de 08 de março de 2016. Implanta o Ensino Médio com Mediação Tecnológica nas escolas da rede pública estadual de ensino. 2016b.

RONDÔNIA. Ata da 32ª audiência pública para debater sobre a implantação do ensino tecnológico no estado de Rondônia. Diário oficial eletrônico da Assembleia Legislativa de Rondônia, 23 de julho de 2016c. Disponível em:

https://www.al.ro.leg.br/transparencia/diario-oficial/2016/edicao-nr-124-de-22-072016.pdf. Acesso em: 30 de julho de 2016.

RONDÔNIA. Projeto de Lei (PL) 424 de 14 de junho de 2016. Institui o projeto de Ensino Médio com mediação tecnológica no âmbito da secretaria do Estado de Educação e dá outras providências. 2016d. Disponível em: http://ditel.casacivil.ro.gov.br/cotel/Livros/Files/L3846.pdf. Acesso em: 15 agosto 2016.

RONDÔNIA. Lei n. 3.846, de 4 de julho de 2016e. Institui o Projeto Ensino Médio com Mediação Tecnológica no âmbito da Secretaria de Estado da Educação e dá outras providências. Diário Oficial do Estado de Rondônia, Rondônia, RO, DOE no 121, Porto Velho, 04/07/2016. 

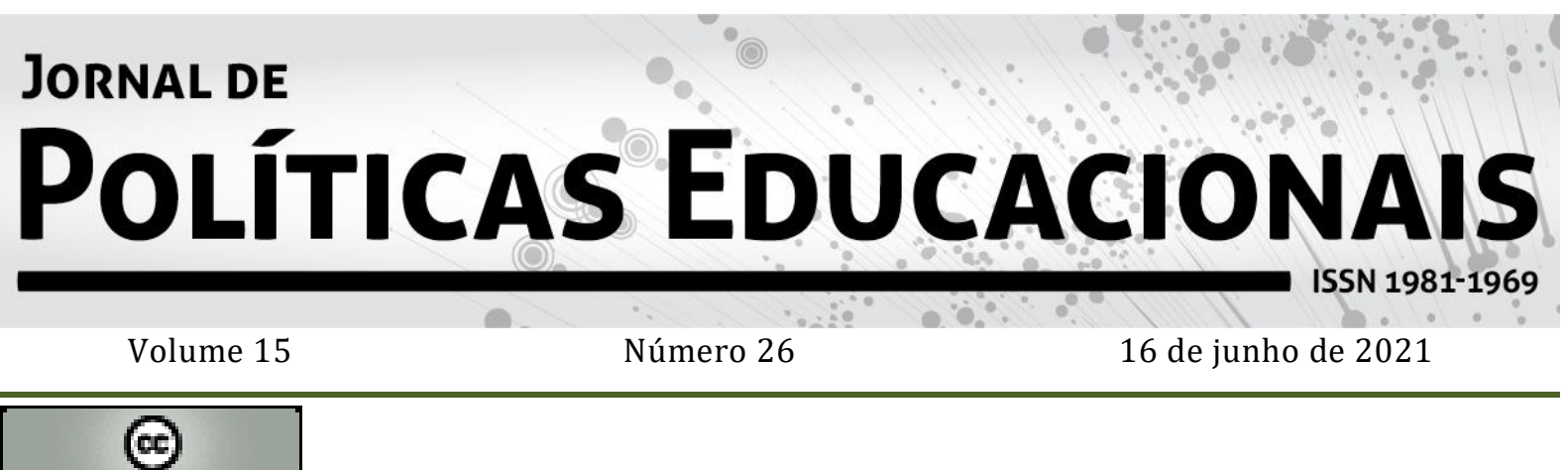

SORERIGHIS RESERVED O Copyright é retido pelo/a autor/a (ou primeiro co-autor) que outorga o direito da primeira publicação ao Jornal de Políticas Educacionais. Mais informação da licença de Creative Commons encontram-se em http://creativecommons.org/licenses/by-nc-nd/2.5. Qualquer outro uso deve ser aprovado em conjunto pelo/s autor/es e pelo periódico.

JoRnAl DE Políticas EduCACIONAIS é uma publicação do Núcleo de Políticas Educacionais do Setor de Educação da Universidade Federal do Paraná - NuPE/UFPR, em consórcio com a Linha de Pesquisa em Políticas Educacionais do Programa de Pós-Graduação em Educação - PPGE/UFPR, que aceita colaboração, reservando-se o direito de publicar ou não o material espontaneamente enviado à redação. As colaborações devem ser enviadas ao NuPE/UFPR, conforme orientações contidas nas páginas do periódico na internet: http://revistas.ufpr.br/jpe.

INDEXAÇÃO:

$\begin{array}{cc}\text { BASE DE DADOS } & \text { ÍNDICES } \\ \text { Sumário.Org } & \text { Index Copernicus } \\ \text { Google Scholar } & \text { Cite Factor } \\ \text { BASE } & \\ \text { Dimensions } & \text { PORTAIS } \\ \text { Miar } & \text { LiVre } \\ & \text { Capes } \\ \text { DIRETÓRIOS } & \text { Science Open } \\ \text { Diadorim } & \text { World Wide Science } \\ \text { DOAJ } & \\ \text { Erih Plus } & \\ \text { Latindex } & \\ \text { EZB } & \\ \text { ROAD } & \\ \text { Journal 4-free } & \\ \end{array}$

(Periódico integralmente disponível apenas em via eletrônica)

Jornal de Políticas Educacionais / Núcleo de Políticas Educacionais da Universidade Federal do Paraná NuPE/UFPR - v.1, n. 1 (1ํㅗ semestre de 2007) - Curitiba: NuPE/UFPR.

Volume 15, número 26 - Junho de 2021

ISSN 1981-1969

1. Educação - Periódicos. 2. Política Educacional - Periódicos. I. NuPE/UFPR 
FERRAZZO, G.; GOMES, M. A. de O. A reforma do ensino médio e a legitimação da educação a distância: o nó obsceno da mediação tecnológica

Comitê Editorial:

Elisângela Scaff (UFPR)

Daniela de Oliveira Pires (UFPR)

Conselho Editorial:

Andréa Barbosa Gouveia (UFPR - Brasil), Angela Maria Martins (FCC, Brasil), Antonia Almeida Silva (UEFS, Brasil), Cesar Tello (Universidad Nacional Tres Febrero, Argentina), Cristiane Machado (Unicamp- Brasil), Elton Luiz Nardi (UNOESC, Brasil), Fernanda Saforcada (Universidad de Buenos Aires - UBA - Argentina), Gladys Beatriz Barreyro (USP - Brasil), Gilda Cardoso Araújo (UFES - Brasil), Gustavo Enrique Fischman (Arizona State University - USA), Janete Maria Lins de Azevedo (UFPE, Brasil), Jefferson Mainardes (UEPG Brasil), João Ferreira de Oliveira (UFG - Brasil), Jorge Manuel Gorostiaga (UNSAM - Argentina), Juca Gil (UFRGS - Brasil), Luciana Rosa Marques (UFPE, Brasil), Luiz Souza Júnior (UFPB - Brasil), Marcia Aparecida Jacomini (Unifesp-Brasil), Maria Dilnéia Espíndola Fernandes (UFMS, Brasil), Ney Cristina Monteiro de Oliveira (UFPA - Brasil), Nicolás Bentancur, (Universidad de la República de Uruguay), Nora Krawczyk (Unicamp- Brasil), Pedro Flores-Crespo (UAQ, México) Rodrigo da Silva Pereira (UFBA, Brasil), Robert Verhine (UFBA - Brasil), Rosana Cruz (UFPI - Brasil), Rubens Barbosa Camargo (USP - Brasil), Sebastián Donoso Díaz (Universidad de Talca - Chile), Theresa Adrião (UNICAMP - Brasil), Vera Maria Vidal Peroni (UFRGS - Brasil).

Créditos e Agradecimentos:

Revisão de Língua Portuguesa, Abstract e Resumen: Programa de apoio às publicações científicas periódicas da UFPR

Arte e diagramação: Tiago Tavares (tiagotav@gmail.com)

Jornal de Políticas Educacionais

Universidade Federal do Paraná

Setor de Educação

Núcleo de Políticas Educacionais - NuPE/UFPR

Avenida Sete de Setembro, 2645

20 andar, Sala 213

80.230-010 - Curitiba - PR - Brasil

Tel.: 41-3535-6264

jpe@ufpr.br

http://revistas.ufpr.br/jpe 